\title{
Fecundidade da mulher paulista abaixo do nível de reposição
}

LÚ CIA MAYUMI YAZAKI

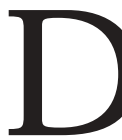

URANTE a última década, um aspecto relativamente novo vem caracterizando as po pulações em diversos países, primeiramente naqueles da E Uropa e em outros mais desenvolvidos, estendendo-se, aos poucos, também naqueles em desenvolvimento, como em alguns lugares da Ásia. N estes países, os casais têm tido, em média, menos de dois filhos, o que não é suficiente para a substituição de suas próprias gerações, ou seja, estes países têm registrado fecundidade abaixo do nível de reposição. Se esse padrão de baixa fecundidade continuar, a população deverá diminuir, além de haver mudança na estrutura etária da população, com a diminuição de crianças e jovens, por um lado, e aumento da população idosa, por outro.

O s últimos levantamentos das N ações U nidas indicam que, entre 1995 e 2000, a fecundidade no mundo era de 2,8 filhos por mulher, sendo que 59 países registravam nível de fecundidade inferior a 2,1 (43 localizados em regiões mais desenvolvidas) e 133 países registravam taxas iguais ou superiores a 2,1 filhos; entre eles, 47 ainda possuíam taxas superiores a cinco filhos por mulher ( $H$ enning, 2003).

No Brasil, os resultados do censo demográfico de 2000 indicam que a fecundidade era de 2,4 filhos por mulher, ou seja, uma redução de $16 \%$ em relação à taxa de 2,9, registrada em 1991 e de 60\%, em relação à fecundidade de 6,2 fiIhos, estimada em 1940. Entre as regiões brasileiras, a Sudeste registrou a menor taxa, de 2,1 filhos por mulher, igual ao da reposição, e as regiões Sul e C entro0 este, taxas de 2,2 . As regiões $N$ orte e $N$ ordeste continuam a apresentar as maiores taxas de fecundidade, de 3,2 e 2,6 respectivamente, embora a redução no período 1991-2000 tenha sido muito importante (24\% e $30 \%$ ).

A fecundidade no Estado de São Paulo alcançou o nível de reposição nos primeiros anos do novo milênio. Essa evolução era esperada, pois a queda da fecundidade foi acelerada nos primeiros anos da década de 1980 e foi contínua até a de 1990, atingindo taxas de 2,3 filhos por mulher.

Assim como a taxa do Brasil retrata a diversidade de situações observadas nas diferentes regiões, a fecundidade do Estado de São Paulo reflete o comportamento médio das mulheres paulistas. D e fato, a fecundidade já havia registrado valores abaixo do nível de reposição em diversas regiões administrativas em que 
- Estado está dividido, em meados da década de 1990, chegando inclusive a valores bastante baixos em relação aos observados em diversos países da Europa no mesmo período. Entretanto, as características do comportamento reprodutivo das mulheres paulistas e aquelas do outro hemisfério não se assemelham, assim como os determinantes associados à queda da fecundidade.

D essa forma, este artigo tem como objetivo apresentar um panorama da fecundidade no Estado de São Paulo e em suas regiões administrativas, que se caracterizam por terem atingido taxas abaixo do nível de reposição em princípios deste século. $\mathrm{N}$ a primeira parte descreve-se a evolução da fecundidade no Estado e em suas regiões. Serão dadas ênfase na análise dos níveis e dos padrões etários da fecundidade e sua evolução a partir dos anos de 1960 ou 1980, conforme a região. O s resultados observados na real idade paulista serão comparados aos dados de vários países onde a fecundidade está abaixo do nível de reposição há mais tempo, destacando-se as diferenças existentes no processo de diminuição da fecundidade dessas populações. $\mathrm{N}$ a etapa seguinte, apresenta-se a fecundidade das mulheres pertencentes a diversos estratos sociais, uma vez que a queda não se restringe a um determinado grupo, mas tem ocorrido de forma generalizada em toda a população, reduzindo as diferenças do número de filhos entre as mulheres e tornando esse processo de queda praticamente irreversível. Por fim, faz-se uma breve apresentação das conseqüências da queda da fecundidade, especificamente do processo de envelhecimento da população no Estado de São Paulo.

Asinformações dos nascimentos para o cál culo da fecundidade deste estudo são provenientes do Registro Civil e das D eclarações de $\mathrm{N}$ ascidos Vivos, estas últimas processadas em São Paulo a partir de 1993. O Estado de São Paulo conta com um sistema de informações que já ultrapassa um século, mas somente a partir do final da década de 1960 é possível conhecer os níveis de fecundidade obtidos por meio das informações de nascidos vivos por idade da mãe. No caso do Estado de São Paulo, o Registro Civil constitui uma fonte importante de informações, pois as estatísticas vitais apresentam alta cobertura e boa qual idade, permitindo acompanhar a evolução demográfica com muita proximidade e de forma contínua, sinalizando as alterações que possam estar ocorrendo (C amargo e Yazaki, 2002). Além disso, possibilita estimar os indicadores para as mais diferentes áreas, o que nem sempre é possível com outras pesquisas. Por sua vez, - Censo Demográfico e a PN AD constituem fontes de informação de grande importância, ambas produzidas pelo IBGE. Sua importância é imensurável em muitas regiões brasileiras, onde foram ou ainda é, a única fonte confiável para estimar a fecundidade; além disso, é, de forma geral, as que permitem revelar o comportamento reprodutivo das mulheres segundo características, como instrução, raça/ cor ou renda, que destacam as diferenças da po pulação segundo grupos sociais. N este estudo serão utilizados também os resultados dos censos demográficos de 1991 e 2000, os quais permitirão destacar as diferenças do comportamento reprodutivo das mulheres de diferentes grupos sociais, assim como 
a sua evolução nesta última década, quando uma grande parte delas atingiu o nível de reposição. As informações de fecundidade de outros países, que serão apresentados a título de comparação, foram obtidas em U nited N ations (2000) e em H enning (2003).

\section{E volução da fecundidade no E stado de São Paulo e em suas regiões}

A evolução da fecundidade em São Paulo a partir da década de 1960 é apresentada no Gráfico 1. E m 1960, a taxa de fecundidade total (TFT) ${ }^{1}$ al cançava 4,69 filhos por mulher e a sua queda foi contínua nos anos seguintes. E ntre 1970 e 1975, a diminuição foi mais acentuada, alcançando 3,37 filhos por mulher; entretanto a fecundidade praticamente manteve-se constante no período seguinte, 1975-1980. D essa forma, a diminuição no período 1960-1980 foi de 1,3 filho ou de aproximadamente $28 \%$. As estimativas no início da década de 1980 indicam queaté 1982 a TFT ainda se mantinha em torno de 3,4 filhos. É a partir de 1983 que a fecundidade voltou a diminuir com rapidez, chegando a 2,33 filhos em 1991 (variação de $32,1 \%$ ou um filho). N os anos seguintes, a fecundidade estabilizou-se em torno de 2,3 filhos por mulher, e no final da década registrou-se até um pequeno aumento nas taxas de fecundidade, para, em seguida, apresentar uma diminuição no período 1998-2002. Assim, em 2000, a fecundidade foi de 2,16 filhos e, em 2002, a taxa era de 1,88 filho por mulher, valor inferior ao nível de reposição².

Gráfico 1

Taxa de Fecundidade Total, Estado de São Paulo 1960-2002.

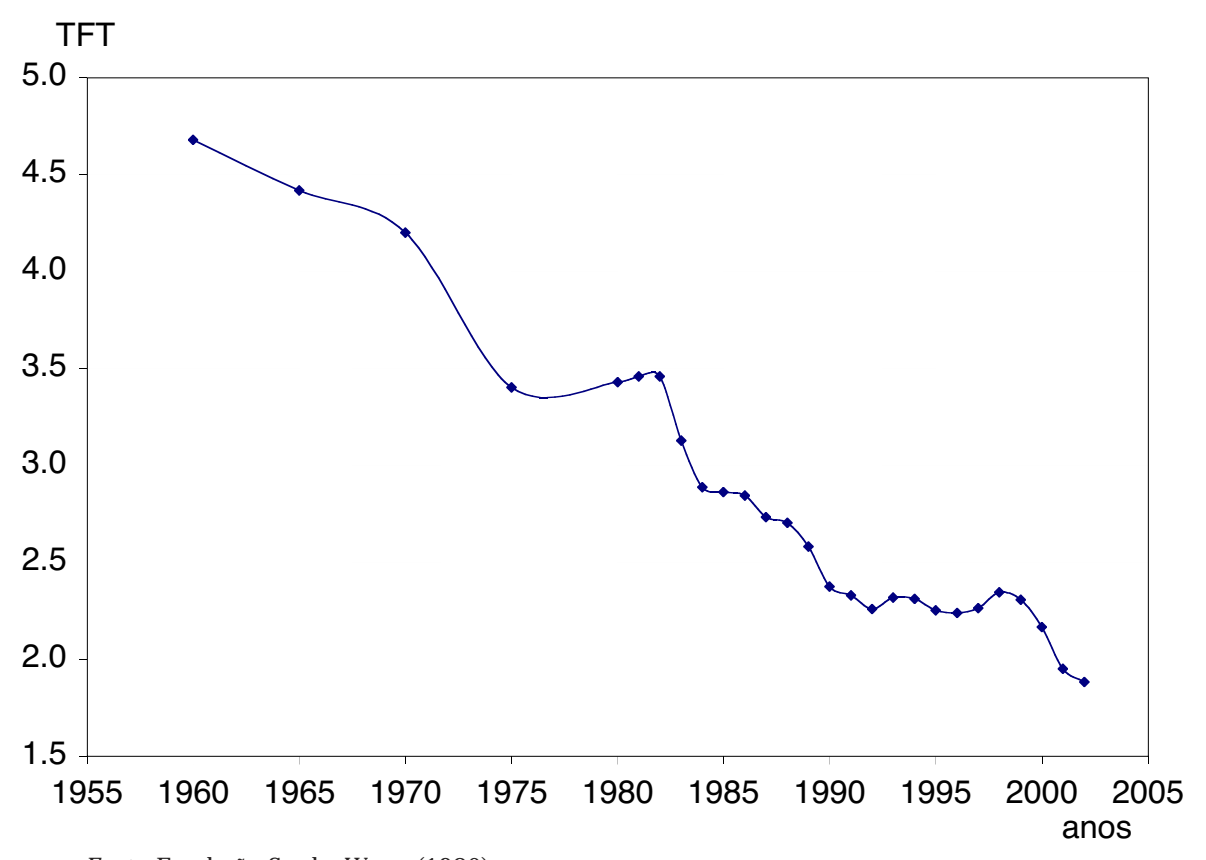

Fonte: Fundação Seade; Wong (1986). 
Para uma avaliação mais precisa da evolução da fecundidade em termos de reposição, dever-se-ia utilizar a taxa de fecundidade por coortes. A TFT, uma medida de período, é utilizada como aproximação, dada a dificuldade de acompanhar a evolução da fecundidade das diferentes coortes, sobretudo das mais jovens. Assim, a TFT pode apresentar uma visão distorcida da evolução da fecundidade por coortes quando ocorrem alterações importantes no ritmo de procriação ou flutuações conjunturais. E ntretanto, a importância da fecundidade do perío do reside no acompanhamento do número anual de nascimentos, que interfere no ritmo de crescimento e na estrutura da população, assim como fornecer insumos para as projeções populacionais.

As taxas de fecundidade para algumas coortes (daquelas que iniciaram a vida reprodutiva aos quinze-dezenove anos em 1965-1969, 1970-1974, ... , 19851989) apresentam diminuição contínua da fecundidade, passando de 2,6 entre as mais velhas, para 1,7 na coorte mais jovem, confirmando a queda já anunciada pelas TFT, indicando que dificilmente haverá recuperação dos níveis de fecundidade (Perpétuo e Wong, 2003).

\section{$\mathbf{N}$ ível e tendência da fecundidade nas R egiões Administrativas do E stado de São Paulo}

A fecundidade, nas quinze regiões em que o E stado de São Paulo encontrase dividido, a partir de 1980, pode ser observada na Tabela 1. Em 1980, os níveis de fecundidade ultrapassavam a média de três filhos em todas as regiões, chegando a quatro em Sorocaba e a 5,5 em R egistro. A penas cinco anos depois, ou seja, em 1985, somente três regiões - Registro, Sorocaba e São J osé dos C ampos - apresentavam taxas superiores a três filhos, que ficaria reduzida apenas à primeira em 1991. N esse ano, já se encontram regiões com níveis de fecundidade próximos ou iguais ao da reposição, casos de São J osé do R io Preto, A raçatuba e M unicípio de São Paulo. A magnitude de queda a níveis tão baixos, em áreas relativamente extensas e com grande número de municípios, como são os casos das regiões administrativas, tem surpreendido os estudiosos, assim como a expansão rápida dessa tendência em todo o Estado e em espaço de tempo tão curto. Em 1995, outras regiões, como Santos, C ampinas, Presidente Prudente, Barretos e a C entral apresentavam taxas de aproximadamente 2,1 filhos por mulher e aquelas com menor fecundidade registraram taxas inferiores a dois. Em 2000, dez das quinze regiões apresentaram fecundidade abaixo do nível de reposição e, em 2002, apenas a região de R egistro mantinha uma taxa superior a dois filhos (Tabela 1).

Em 2002, as regiões que apresentavam baixa fecundidade na década anterior mantiveram a tendência de diminuição, alcançando taxas inferiores a 1,6 filho por mulher, como eram os casos de São J osé do Rio Preto e Araçatuba, níveis considerados surpreendentes mesmo para o E stado de São Paulo. A média do Estado mantém-se mais próxima a dois filhos devido às taxas das regiões da Grande São Paulo, Sorocaba, Santos e São J osé dos Campos, cujas populações 
correspondem a $65 \%$ do total do Estado. N esse panorama, chama a atenção a situação do M unicípio de São Paulo, que apresenta taxas mais elevadas que a maioria das regiões do Estado, situação inversa à observada entre 1980 e início da década de 1990, quando aparecia entre as menores. O bserva-se que foi a única área em que a fecundidade foi maior em 2000, em relação ao período anterior (Tabela 1).

$\mathrm{N}$ a mesma tabela apresentam-se as diminuições relativas das taxas nos diferentes períodos. A queda é superior a $30 \%$ em praticamente todas as regiões no perío do 1980-1991, que, em muitos casos, significou a redução de um filho, tendo como conseqüência diminuição no ritmo de crescimento populacional, redução no tamanho das famílias, entre outros. A variação na década seguinte foi menor, mas igualmente importante, o que, no cômputo final, significou que a fecundidade em todas as regiões caiu quase pela metade entre 1980 e 2002.

Tabela 1

Taxa de Fecundidade Total (TFT),

Regiões Administrativas do Estado de São Paulo 1980-2002.

\begin{tabular}{|l|c|c|c|c|c|c|r|}
\hline \multirow{2}{*}{\begin{tabular}{c} 
Regiões \\
\multicolumn{1}{c}{ Administrativas }
\end{tabular}} & \multicolumn{4}{c}{ TFT } & \multicolumn{3}{c|}{ Variação da TFT (\%) } \\
\cline { 2 - 9 } & 1980 & 1991 & 2000 & 2002 & $1980 / 91$ & $1991 / 02$ & $1980 / 02$ \\
\hline Estado de São Paulo & $\mathbf{3 , 4 3}$ & $\mathbf{2 , 3 3}$ & $\mathbf{2 , 1 6}$ & $\mathbf{1 , 8 8}$ & $-\mathbf{3 2 , 1}$ & $-\mathbf{1 9 , 2}$ & $-\mathbf{4 5 , 2}$ \\
\hline Grande São Paulo & 3,38 & 2,29 & 2,31 & 1,99 & $-32,1$ & $-13,4$ & $-41,2$ \\
\hline Município de São Paulo & 3,17 & 2,18 & 2,29 & 1,97 & $-31,1$ & $-9,8$ & $-37,9$ \\
\hline Demais Municípios & 3,85 & 2,48 & 2,35 & 2,01 & $-35,6$ & $-19,0$ & $-47,8$ \\
\hline Registro & 5,50 & 3,16 & 2,71 & 2,38 & $-42,5$ & $-24,7$ & $-56,8$ \\
\hline Santos & 3,40 & 2,26 & 2,22 & 1,92 & $-33,5$ & $-14,9$ & $-43,5$ \\
\hline São José dos Campos & 3,80 & 2,54 & 2,15 & 1,87 & $-33,3$ & $-26,2$ & $-50,8$ \\
\hline Sorocaba & 4,00 & 2,71 & 2,28 & 1,99 & $-32,2$ & $-26,6$ & $-50,2$ \\
\hline Campinas & 3,26 & 2,31 & 1,95 & 1,72 & $-29,3$ & $-25,6$ & $-47,4$ \\
\hline Ribeirão Preto & 3,26 & 2,28 & 2,02 & 1,81 & $-29,9$ & $-20,6$ & $-44,3$ \\
\hline Bauru & 3,49 & 2,28 & 1,97 & 1,74 & $-34,6$ & $-23,7$ & $-50,1$ \\
\hline São José do Rio Preto & 3,18 & 2,11 & 1,64 & 1,47 & $-33,7$ & $-30,5$ & $-53,9$ \\
\hline Araçatuba & 3,29 & 2,06 & 1,74 & 1,54 & $-37,3$ & $-25,3$ & $-53,2$ \\
\hline Presidente Prudente & 3,50 & 2,20 & 1,87 & 1,68 & $-37,1$ & $-23,4$ & $-51,8$ \\
\hline Marília & 3,58 & 2,30 & 1,97 & 1,71 & $-35,9$ & $-25,5$ & $-52,3$ \\
\hline Central & 3,22 & 2,26 & 1,79 & 1,61 & $-29,6$ & $-28,7$ & $-49,9$ \\
\hline Barretos & 3,44 & 2,34 & 1,81 & 1,65 & $-32,2$ & $-29,5$ & $-52,1$ \\
\hline Franca & 3,31 & 2,40 & 2,07 & 1,92 & $-27,5$ & $-20,2$ & $-42,2$ \\
\hline
\end{tabular}

Fonte: Fundação Seade.

Esses resultados mostram que a redução da fecundidade é generalizada, pois está ocorrendo até em áreas de baixo nível desenvolvimento socioeconômico do Estado, fenômeno que também é observado nas demais regiões do país. 
A través do M apa 1 é possível visualizar a evolução da fecundidade nas regiões do Estado no período 1980-2002; observa-se que as regiões com os menores níveis ocupam uma área contínua ao norte do Estado e, à medida que as taxas aumentam, avança-se em direção sul; por outro lado, observa-se a tendência ao clareamento do mapa ao longo do tempo, indicando que a situação da fecundidade mudou radicalmente desde a década de 1980 nas regiões do Estado, com uma tendência à homogeneização dos níveis.

\section{E volução da fecundidade por idade}

A evolução dosníveis de fecundidade é acompanhada pelas transformações na estrutura da fecundidade por idade da mulher, que fornecem elementos para a compreensão da transição da fecundidade. A redução do número médio de filhos por mulher, provocada pelos novos padrões de comportamento reprodutivo, ocorreu em todas as faixas etárias, como pode ser visualizado Gráfico 2. A fecundidade diminui em todas as faixas etárias, mas, em especial, nas mulheres com mais de trinta anos, concentrando-se, assim, entre vinte e trinta anos. Em São Paulo, como em todo o país, a fecundidade das adolescentes é elevada quando comparada à de outros países (da Europa ou J apão). D essa forma, a fecundidade em São Paulo caracteriza-se por atingir baixos níveis, com uma estrutura jovem, isto é, a fecundidade é mais elevada entre vinte e 25 anos e diminuindo nas demais idades, caracterizando-se como curva com cúspide do tipo precoce.

\section{Gráfico 2}

Taxas de Fecundidade por I dade, Estado de São Paulo 1960-2002.

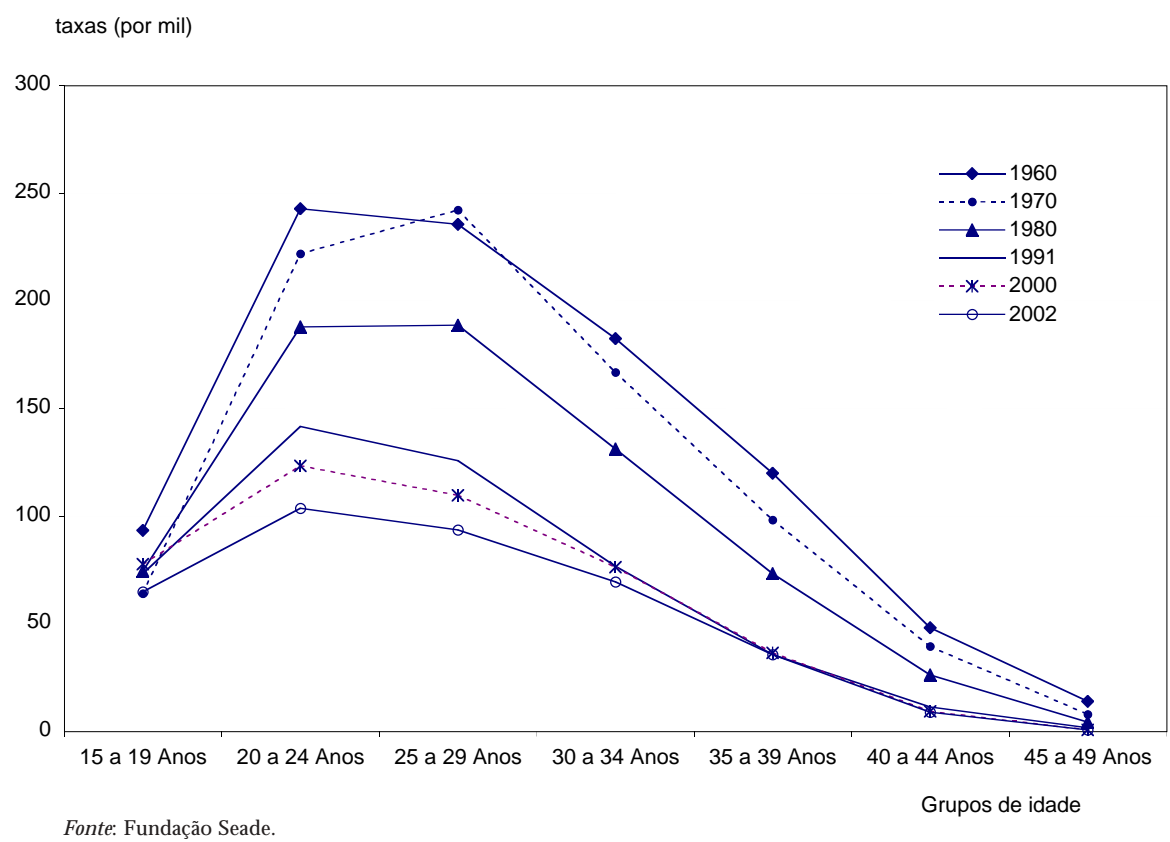




\section{M apa 1}

Taxa de Fecundidade Total, Estado de São Paulo, 1980-2002.

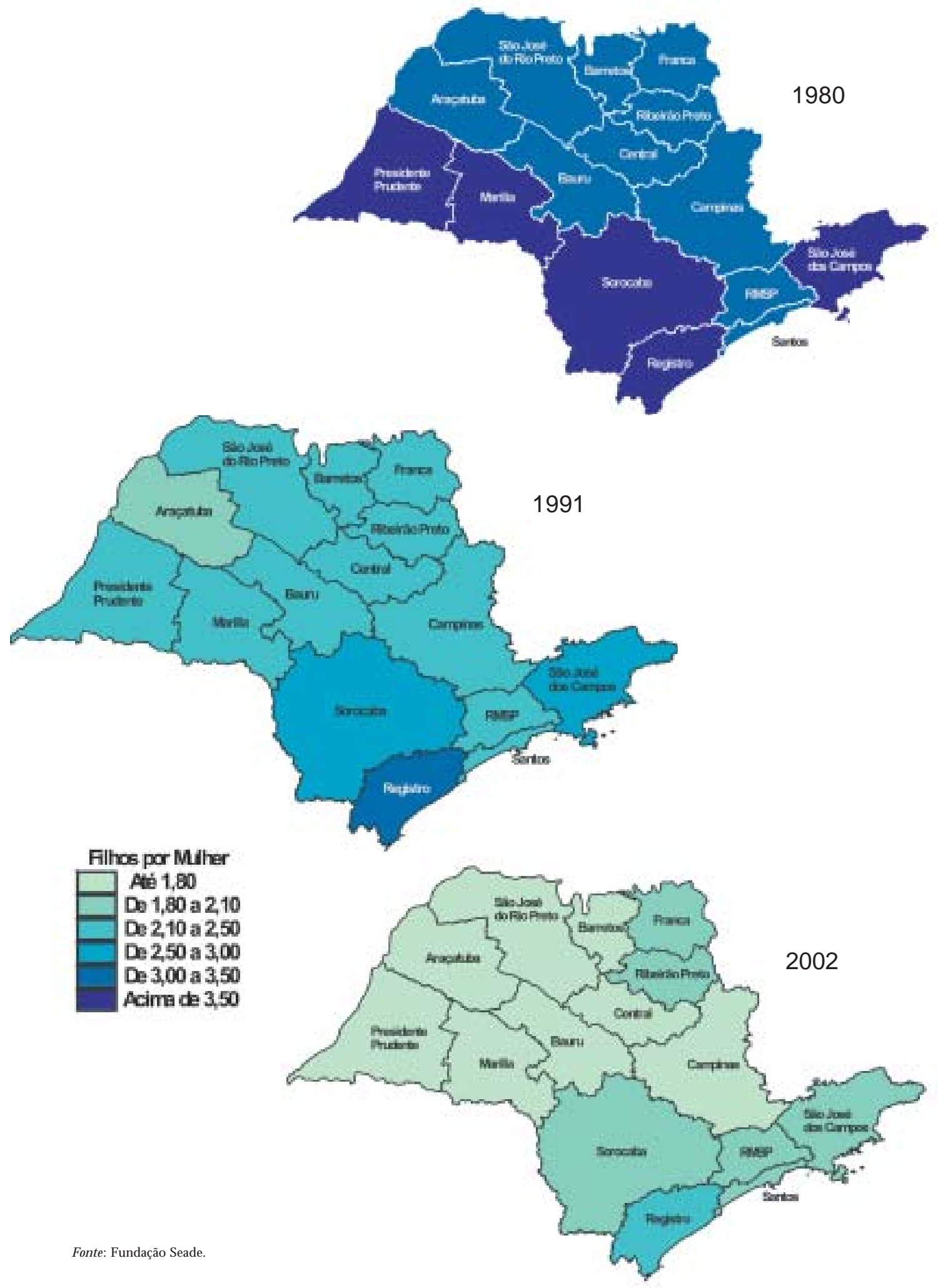


Entre 1960 e 1980, a fecundidade do grupo de quinze a dezenove anos diminuiu de 93 para 74 nascimentos para cada mil mulheres desse grupo etário, mas nos anos seguintes, a fecundidade das adolescentes, como foi denominada, passou a apresentar aumento, chegando a 86 por mil no final da década. Somente a partir de 2000 as taxas têm mostrado sinais de redução, registrando inclusive taxas inferiores às da década de 1980, chegando a aproximadamente 65 por mil, uma diminuição superior a $20 \%$ em menos de cinco anos. Este fenômeno da fecundidade elevada entre as adolescentes ${ }^{3}$ é uma característica de algumas realidades, sobretudo da América L atina, pois nos países da Europa ou da Ásia ela é bastante reduzida 4 . Assim, dos países da América $L$ atina podem ser citados a Cuba de 1990, com fecundidade de 1,8 filho por mulher, que apresentava uma taxa de quinze a dezenove anos de 71 por mil, ou o Chile, cuja TFT era de 2,4 no período 1995-2000, com uma taxa menor, de 49 por mil. D os países desenvolvidos pode-se citar o Japão, com TFT de 1,4 em 1994 e que registra uma das taxas mais baixas no grupo das adolescentes, de quatro por mil; nos países da Europa ocidental, a fecundidade total variava entre 1,3 e 1,7 filho por mulher, em 1995, e a do grupo de quinze a dezenove anos oscilava entre cinco e dez por mil. Os Estados U nidos, embora pertencente ao grupo dos desenvolvidos, registrava, em 1994, fecundidade adolescente relativamente elevada, de sessenta por mil, com a TFT de 2,07 filhos por mulher. Essas estatísticas indicam, em geral, que, nesses últimos países, a entrada na maternidade é adiada em favor de níveis mais elevados de educação e/ ou maiores experiências profissionais. N os casos do Estado de São Paulo e do Brasil, análises mostram que a fecundidade da adolescente não é homogênea nos grupos sociais, como será visto com mais detalhe ao longo deste trabalho, ou seja, embora o fenômeno ocorra em toda a população, as taxas são maiores entre os grupos menos favorecidos, como as que têm menor nível de instrução, pois entre as mais instruídas as taxas são menores. C abe lembrar que o fenômeno mensurável é o da fecundidade e não o da gravidez, cujas informações são inexistentes.

A partir dos vinte anos, a diminuição da fecundidade foi importante em todo o período e as maiores reduções ocorreram entre as mulheres com mais de 35 anos de idade, alterando o padrão de fecundidade por idade.

Entre 1960 e 1970, a fecundidade das mulheres de vinte a 24 e 25 a 29 anos era muito semelhante e superava 220 nascimentos por mil mulheres. $\mathrm{Em}$ 1970, a fecundidade das primeiras registra um declínio de 8,6\%, mas o grupo de 25 a 29 apresenta um pequeno aumento, alterando a estrutura da curva ( $G$ ráfico 2). No perío do seguinte, a diminuição é de 15 e $22 \%$ respectivamente e a cúspide da curva (ponto mais alto) permanece nesses dois grupos de idade, com uma taxa de 188 nascimentos por mil mulheres. Entre 1980 e 1991, a queda é maior entre as mulheres de 25 a 29 anos $(33,4 \%)$ e a cúspide passa para o grupo mais jovem, permanecendo até hoje, segundo as últimas estatísticas. Atualmente, a fecundidade das mulheres de vinte a 29 anos está em torno de cem nascimentos por mil mulheres, resultado de uma redução de 60\% no período 1960-2000. 
A fecundidade das mulheres de trinta a 34 anos e de 35 a 39 anos foi reduzida em 30 e 40\%, respectivamente, no período 1960-1980, mas no seguinte, 1980-1991, a queda chega a 50\%, ou seja, as taxas destes grupos caem pela metade. As pesquisas de anticoncepção da PN AD, assim como a de demografia e saúde organizada pela B emfam, ambas de 1986, revelam pela primeira vez a prevalência da anticoncepção entre as mulheres unidas, sendo superior a $75 \%$ no caso de mulheres com mais de 25 anos e mostram que a esterilização feminina éo principal meio utilizado para controlar, ou melhor, limitar a fecundidade nessas faixas etárias 5 . Entre 1991 e 2002, a redução da fecundidade do grupo de trinta a 34 anos é de 9,5\%e a taxa é de 69 nascimentos por mil mulheres; no grupo seguinte, a fecundidade permaneceu em 36 filhos por mil mulheres e no período 19602002, a fecundidade diminuiu em 62 e $70 \%$ respectivamente.

Embora as taxas sejam bastante reduzidas, a variação da fecundidade das mulheres de quarenta a 44 e 45 a 49 anos foi superior aos dos grupos anteriores,

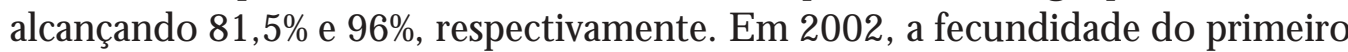
grupo é de nove filhos por mil mulheres e no último, inferior a um.

Esses resultados mostram que a estrutura da fecundidade de São Paulo passou a ser do tipo precoce a partir dos anos de 1980, onde a fecundidade mais elevada concentra-se no grupo de vinte a 24 anos. 0 utra maneira de examinar essas mudanças estruturaisé através do peso relativo da fecundidade das mulheres de cada faixa etária com relação à fecundidade total. Os dados indicam que a importância relativa dos grupos mais jovens vem aumentando desde os anos de 1960, sinalizando para a precocidade da fecundidade das mulheres residentes no Estado de São Paulo.

A contribuição relativa da fecundidade das jovens de quinze a dezenove anos, que era de $10 \%$ no início do período aumentou, principalmente na década de 1980, passando a 15,7\% em 1991 para 18\% em 2000. Com a queda da fecundidade em 2002, sua contribuição também foi reduzida para $17,2 \%$ A das mulheres de vinte a 24 anos aumenta de $26 \%$ a 30\%entre 1960 e 1991 e diminui ligeiramente, para 28\%, no início do ano 2000. A maior contribuição do grupo de 25 a 29 anos foi de $28 \%$ entre 1970 e 1980, quando a curva era do tipo dilatada; atualmente, ela oscila em torno de $25 \%$. 0 grupo seguinte, de trinta a 34 anos, que contribuía com aproximadamente $20 \%$ da fecundidade total no início do período, passou a contribuir com 16,5\% em 1991, voltando a 18\% no final do período. A partir dos 35 anos, a contribuição é pequena e a tendência tem sido de redução no tempo, embora possa haver uma pequena recuperação caso a fecundidade das adolescentes continue a diminuir. $D$ essa forma, as mulheres entre quinze e trinta anos, residentes em São Paulo, contribuem cada vez mais para a fecundidade total, passando de $61 \%$ em 1960 para $66 \%$ em 1980, e para 70\% em 2002, quando a fecundidade estava abaixo do nível de reposição.

Essa precocidade da fecundidade, quando comparada com a dos países que atingiram o nível de reposição há mais tempo, é somente comparável à dos Estados 
U nidos, em 1994, cuja contribuição da faixa etária de quinze a 29 anos somava $72 \%$ (a de C uba somava $79 \%$ em 1991). N os demais países, a contribuição maior é proveniente das mulheres de vinte a 34 anos, já que a do grupo de quinze a dezenove anos é muito pequena (inferior a $5 \%$ nos países da E uropa ou da Ásia); além disso, as taxas mais elevadas situam-se no grupo de 25 a 29 anos. A diminuição da fecundidade aos níveis inferiores ao da reposição provocou alterações no padrão etário da fecundidade em alguns destes países, pois passaram de uma curva do tipo precoce ou dilatada (taxas mais elevadas entre vinte e 25 anos ou entre vinte e trinta anos, respectivamente) para uma do tipo tardia (com a cúspide entre 25 e trinta anos). Essas mudanças foram observadas em vários países da Europa O cidental, da Escandinávia e do Reino U nido. Em al guns casos, como na I tália e E spanha, a cúspide deslocou-se mais, passando a ser do tipo dilatada, entre 25 e 35 anos, sendo que na $\mathrm{H}$ olanda a cúspide está entre as mulheres de trinta a 34 anos, caracterizando uma fecundidade muito mais tardia.

A medida-resumo desse padrão etário é a idade média da fecundidade. No E stado de São Paulo, a idade média era de 28,5 anos em 1960, tendo diminuído para 27,8 em 1980. A queda acelerada e a precocidade da fecundidade reduziram ainda mais a idade média para 26,4 anos em 1991, que se manteve em 2000. Em 2002, houve uma pequena recuperação, e a idade média foi calculada em 26,7 anos. Em comparação às mulheres da E uropa $O$ cidental ou da Ásia, as paulistas são, em geral, três anos mais jovens e se igualam às americanas. Entretanto, em todos estes países, a tendência foi de aumento da idade média, contrária à registrada em São Paulo.

Essas diferenças evidenciam que os fatores que levaram à redução da fecundidade nesses países não se reproduzem em nossa realidade.

A precocidade da fecundidade das mulheres do Estado de São Paulo pode ser compreendida pelo seu comportamento contraceptivo. Em 1996, 79\% das mulheres unidas de quinze a 49 anos utilizavam al gum método anticoncepcional, sendo que a pílula e a esterilização feminina eram adotadas por $55 \%$ das mulheres, prevalência esta que não se havia alterado em relação aos dados de 1986; entretanto, houve um aumento na utilização de outros métodos, entre eles o preservativo e outros modernos, que representavam apenas 16,5\% de usuárias. As análises da prevalência contraceptiva mostram que a pílula é utilizada para controlar e espaçar os nascimentos, enquanto a esterilização é adotada para limitar o tamanho da prole; além disso, mostram que a esterilização está ocorrendo em mulheres cada vez mais jovens e, em geral, quando elas têm dois ou, no máximo, três filhos (Perpétuo e Wajnman, 1993; Yazaki, 2002; entre outros). Considerando que a maternidade ou o nascimento do primeiro filho ocorre em mulheres cada vez mais jovens, não é de se estranhar que elas desejem encerrar a sua vida reprodutiva mais cedo, uma vez que ela tenha o número desejado de filhos (que é de aproximadamente dois, segundo as pesquisas demográficas) optando, para isso, por um método definitivo de contracepção. 
Apesar da heterogeneidade socioeconômica do Estado de São Paulo, as estruturas de fecundidade por idade nas R egiões Administrativas são semelhantes, ou seja, as curvas são do tipo precoce, com cúspide entre vinte e 25 anos; a diferença é dada pelas taxas que variam conforme o nível de fecundidade da região. O Município de São Paulo, que detinha uma das menores taxas de fecundidade em 1980, apresentou uma curva com cúspide tardia nesta década, mas passou para a precoce na década seguinte.

A evolução da fecundidade por grupos de idade segue o padrão já apresentado, ou seja, diminuição importante da fecundidade em todos os grupos etários no período 1980-2002, com exceção do primeiro, de quinze a dezenove anos. A fecundidade das adolescentes nesse grupo é superior a setenta nascimentos por mil em 1980, com exceção da capital (sessenta por mil) e a taxa mais elevada é observada na região de maior fecundidade, a de Registro, com taxa de 131,7 por mil. Com exceção desta última, onde a redução foi observada em todo 0 perío do, a tendência observada foi de aumento das taxas, al gumas regiões durante a década de 1990 e outras já a partir de meados da década de 1980. N os últimos períodos, a tendência se inverte e a diminuição das taxas de fecundidade desse grupo é geral no Estado, sobretudo nos primeiros anos dessa década.

Os diferentes indicadores do padrão etário da fecundidade mostram as alterações que ocorreram com a queda da fecundidade nas regiões do Estado. A Tabela 2 apresenta a contribuição relativa da fecundidade das mulheres de quinze a 29 anos no total da fecundidade, assim como a idade média da fecundidade nas Regiões Administrativas em três momentos da transição da fecundidade.

Em 1980, aproximadamente dois terços da fecundidade ocorria entre as mulheres com menos de trinta anos. Com a diminuição da fecundidade, sobretudo das mulheres mais velhas, a contribuição ultrapassa os 70\%, chegando a 80\% naquelas regiões de menor fecundidade. Esse panorama mantém-se até meados da década de 1990 para registrar uma pequena redução no início do ano 2000. Essa concentração da fecundidade em idades jovens teve reflexo na diminuição da idade média da fecundidade, que passou de aproximadamente 27-28 anos para 26-27, implicando em um rejuvenescimento de um ano a dois, conforme a região. As regiões de menor fecundidade registram idades médias ligeiramente mais baixas que as demais.

$\mathrm{N}$ esse conjunto de regiões, destaca-se o comportamento das mulheres residentes na capital, que apresenta a maior idade média, assim como a menor contribuição da fecundidade de quinze a 29 anos no total. N essa área, o peso relativo da fecundidade das mulheres de trinta a 34 anos é ligeiramente superior ao das demais regiões, ou seja, na capital, o peso é de aproximadamente $20 \%$, enquanto nas demais varia entre 16 e 18\% Esse dado pode ser o reflexo do comportamento de um grupo de mulheres que está adiando o início da maternidade, ao contrário daquelas que a conhecem ainda durante a adolescência, talvez até como conseqüência da primeira relação sexual. Assim como no Estado de São Paulo observam-se 
níveis diferenciados de fecundidade segundo as R egiões Administrativas, a capital também apresenta áreas de mais baixa e mais alta fecundidade, estando elas associadas às características socioeconômicas de suas populações.

Tabela 2

Contribuição relativa da fecundidade das mulheres de 15 a 29 anos

na Fecundidade Total e I dade M édia da Fecundidade, Regiões Administrativas do Estado de São Paulo 1980-2002.

\begin{tabular}{|c|c|c|c|c|c|c|}
\hline \multirow[t]{2}{*}{$\begin{array}{c}\text { Regiões } \\
\text { Administrativas }\end{array}$} & \multicolumn{3}{|c|}{$\begin{array}{c}\text { Contribuição da fecundidade de } \\
15 \text { a } 29 \text { anos na TFT (\%) }\end{array}$} & \multicolumn{3}{|c|}{ Idade média da fecundidade } \\
\hline & 1980 & 1991 & 2002 & 1980 & 1991 & 2000 \\
\hline Estado de São Paulo & 65,8 & 73,1 & 69,6 & 27,8 & 26,4 & 26,7 \\
\hline Grande São Paulo & 65,1 & 71,4 & 67,6 & 27,9 & 26,7 & 27,0 \\
\hline Município de São Paulo & 64,7 & 70,3 & 66,4 & 27,9 & 26,9 & 27,1 \\
\hline Demais Municípios & 65,6 & 73,0 & 69,2 & 27,8 & 26,5 & 26,8 \\
\hline Registro & 61,4 & 71,1 & 72,0 & 28,4 & 26,6 & 26,2 \\
\hline Santos & 66,7 & 73,1 & 70,1 & 27,6 & 26,4 & 26,5 \\
\hline São José dos Campos & 64,3 & 72,8 & 70,5 & 28,1 & 26,5 & 26,5 \\
\hline Sorocaba & 63,3 & 72,6 & 71,6 & 28,1 & 26,4 & 26,3 \\
\hline Campinas & 67,7 & 74,8 & 70,4 & 27,5 & 26,2 & 26,5 \\
\hline Ribeirão Preto & 66,8 & 72,8 & 70,7 & 27,6 & 26,5 & 26,4 \\
\hline Bauru & 66,8 & 76,1 & 73,6 & 27,6 & 25,8 & 26,0 \\
\hline São José do Rio Preto & 69,7 & 79,2 & 74,9 & 27,2 & 25,4 & 25,9 \\
\hline Araçatuba & 70,7 & 79,2 & 75,0 & 27,1 & 25,4 & 25,9 \\
\hline Presidente Prudente & 66,4 & 78,6 & 73,7 & 27,8 & 25,6 & 26,1 \\
\hline Marília & 65,7 & 76,6 & 73,8 & 27,8 & 25,9 & 26,0 \\
\hline Central & 68,9 & 76,6 & 73,4 & 27,2 & 25,8 & 26,0 \\
\hline Barretos & 66,6 & 77,2 & 75,3 & 27,7 & 25,6 & 25,7 \\
\hline Franca & 65,5 & 75,2 & 72,0 & 27,8 & 26,1 & 26,3 \\
\hline
\end{tabular}

Fonte: Fundação Seade.

A informação da prevalência contraceptiva nas regiões do Estado é inexistente, pois as amostras das pesquisas permitem apenas estimativas para os totais de alguns Estados brasileiros e para o país. Entretanto, considerando-se que a esterilização está diretamente associada à prática do parto cesáreo, observa-se que existe uma forte coincidência entre o nível de fecundidade e a realização da cesárea nos partos dos nascimentos o corridos anualmente nas diferentes regiões, informações contidas nas declarações de nascimentos. As estatísticas para 0 ano de 2001 indicam que a proporção de partos cesáreos varia de 58 a 65\%em regiões com menores níveis de fecundidade. A região de São J osé do R io Preto é a campeã em realização de cesáreas, registrando valores superiores a $75 \%$ no final da década de 1990. N o outro extremo, encontra-se a região de R egistro, seja com a maior fecundidade, seja com a menor proporção de cesáreas (34,5\%, em 2001). A média 
de partos cesáreos ocorridos no E stado foi de $49 \%$ uma estatística elevada quando se compara com a de outros países e, sobretudo, porque são desnecessárias ${ }^{6}$. D essa forma, é muito provável que a esterilização, associada à cesárea, esteja sendo adotada de forma generalizada pelas mulheres residentes no Estado de São Paulo, a fim de controlar o número de filhos.

\section{N úmero de nascimentos}

A diminuição da fecundidade ocorrida em São Paulo pode ser examinada em termos do número total de nascimentos, assim como pela ordem destes nascimentos. A primeira informação afeta diretamente o tamanho da população, portanto, de grande importância para o planejamento de políticas e programas econômicos, sociais e de saúde. A distribuição de nascimentos pela ordem de nascimento, ou seja, a proporção de primeiros, segundos, ..., n-ésimos filhos é um bom indicador de transformações dos padrões reprodutivos. Assim, quanto maior a fecundidade, maior é a probabilidade de uma mulher ter um segundo, um terceiro etc.; conseqüentemente, em populações de alta fecundidade, a proporção de primogênitos é pequena no total de nascimentos. Por outro lado, quando a fecundidade é baixa, a proporção de primogênitos é alta, chegando a valores próximos aos 50\% (casos de J apão, I tália, Bélgica, para a década de 1990). Além de ser um indicador de mudanças reprodutivas, essas proporções são facilmente obtidas e calculadas, pois dependem apenas do Registro Civil que fornece essa informação (Campanário e Yazaki, 1994).

A evolução dos nascimentos no Estado de São Paulo é conhecida a partir de 1910, quando os dados estão mais completos e consolidados (Camargo e Yazaki, 2002). A partir dessa data, o número de nascimentos aumentou até a metade da década de 1960. Em seguida, apresentou uma diminuição, retomando o crescimento, no entanto, no final da mesma década, chegando a aproximadamente 500 mil nascimentos. Esse aumento prossegue até 1982, quando registra 772 mil nascimentos, o maior no Estado até os dias de hoje. N os anos seguintes, o número de nascimentos cai até cerca de 650 mil no início dos anos de 1990, mas volta a se recuperar, chegando a 734 mil em 1998. A partir do ano seguinte, o número tem diminuído anualmente e as estatísticas do Registro Civil de 2002 indicam que, neste ano, o número de nascimentos girava em torno de $632 \mathrm{mil}$.

Em relação à proporção de primogênitos, os dados para o início dos anos de 1990 indicam que eles correspondem a 40,5\% dos nascimentos ocorridos naquele ano, aumentando para $41,8 \%$ em 2001 . São valores altos, próximos aos de alguns países com baixa fecundidade, como os Estados U nidos, N oruega, Suécia. No caso de nascimentos de ordem dois e três, as proporções somam $46 \%$ em 2001, ligeiramente inferior aos 47,2\% de 1993. O s correspondentes nos países da Europa ou da Ásia superam os 50\% O s nascimentos de ordem superior a quatro correspondem a 12,3\%, em São Paulo, proporção ainda elevada quando se compara com os países de baixa fecundidade, que varia entre 3 e 10\% 
Confirma-se, assim, que no Estado de São Paulo as mulheres têm limitado a sua fecundidade em dois a três filhos, na maioria dos casos, e a esterilização deve ser amplamente adotada para alcançar este resultado.

$\mathrm{N}$ as regiões que compõem o Estado, a proporção de primogênitos em 1993 variava de 35\%, nas regiões de R egistro e Sorocaba, a 45\%, em Araçatuba ou São J osé do Rio Preto. Em 2001, essa proporção aumentou ligeiramente em quase todas as regiões, com exceção das últimas mencionadas. $N$ essas regiões de menor fecundidade, a proporção de nascimentos de ordem dois ou três era de praticamente $50 \%$ e os de ordem superior a quatro era de apenas $7 \%$ No outro extremo, a região de Registro apontava ainda uma proporção importante de nascimentos de ordem superior a quatro, ou seja, de $22 \%$, não havendo situações similares nas demais regiões, cujas proporções variavam entre 10 e 15\%.

Em síntese, os dados apresentados até aqui revelam que o comportamento reprodutivo das mulheres paulistas alterou-se no Estado de São Paulo durante o processo de diminuição da fecundidade: a experiência da maternidade está sendo vivida por muitas jovens adolescentes e as mulheres em geral estão tendo seus filhos mais precocemente do que há vinte anos atrás; além disso, o desejo de uma família menor é cada vez mais marcante, pois a proporção de mulheres com mais de quatro filhos é minoria na população. E, para alcançar tal propósito, elas adotam um método definitivo e em idades cada vez mais jovens.

\section{Fecundidade por nível de instrução das mulheres}

O sníveis de fecundidade das regiões do Estado abaixo do nível de reposição mostram que a redução da fecundidade é uma tendência generalizada. A presentam-se a seguir os níveis de fecundidade segundo o nível de instrução das mulheres, utilizado aqui como proxyde grupos sociais. A associação entre o nível de fecundidade e o grau de instrução das mulheres tem sido historicamente negativa. 0 que se pretende mostrar é que a distância entre as TFT s dos diferentes estratos populacionaisjánão étão grande, como conseqüência da quedageneralizada dafecundidade.

O s estudos que analisam os determinantes da queda da fecundidade no B rasil indicam que o processo da transição da fecundidade iniciou-se com as mulheres pertencentes aos grupos mais privilegiados da população, como as residentes em áreas mais urbanas e as mais instruídas. A partir dos anos de 1980, a tendência de queda generalizou-se em toda a população, trazendo como conseqüência alterações importantes na dinâmica demográfica, por atingir uma parcela muito grande da população. Diversos fatores foram analisados para compreender esta queda que foi bastante acelerada ${ }^{7}$. N os anos de 1990, o declínio foi contínuo, indicando que a tendência era irreversível e que, na década seguinte, a fecundidade alcançaria o nível de reposição, como foi observado para o Estado de São Paulo e praticamente em todas as suas regiões.

0 aumento do nível de escolaridade observada no país tem um papel importante na queda da fecundidade; estudos indicam que o menor número de filhos 
que uma mulher tem está estreitamente associado ao maior nível de instrução, através do início maistardio na formação da família, proporcionando maior acesso ao mercado de trabalho, provocando maior racionalidade reprodutiva, aumentando a capacidade de obter mais informações acerca dos meios contraceptivos, levando a uma relação mais igualitária no interior da família, entre outros (Lam et al., 1992; M artin e Juárez, 1995).

A Tabela 3 apresenta o número médio de filhos das mulheres do $E$ stado de São Paulo e suas regiões segundo o nível de instrução, estimado a partir dos dados censitários de 1991 e $2000^{\circ}$. As mulheres menos instruídas tinham, em média, em 1991, entre três e quatro filhos por mulher, com exceção de Registro, onde a taxa ainda era bastante elevada. N o grupo das mulheres medianamente instruídas, a fecundidade variava entre 2,5 e três filhos e no grupo das mais instruídas, o número era inferior ao nível de reposição no Estado e na maioria das regiões.

Tabela 3

Taxa de Fecundidade Total por nível de instrução da mulher, Regiões Administrativas do Estado de São Paulo 1991-2000.

\begin{tabular}{|c|c|c|c|c|c|c|c|c|}
\hline \multirow{2}{*}{$\begin{array}{c}\text { Regiões } \\
\text { Administrativas }\end{array}$} & \multicolumn{4}{|c|}{1991} & \multicolumn{4}{|c|}{2000} \\
\hline & Total & $\begin{array}{l}\text { Até } 3 \\
\text { Anos }\end{array}$ & $\begin{array}{l}4 \text { a } 7 \\
\text { Anos }\end{array}$ & $\begin{array}{l}8 \text { Anos } \\
\text { ou Mais }\end{array}$ & Total & $\begin{array}{l}\text { Até } 3 \\
\text { Anos }\end{array}$ & $\begin{array}{r}4 \text { a } 7 \\
\text { Anos }\end{array}$ & $\begin{array}{l}8 \text { Anos } \\
\text { ou Mais }\end{array}$ \\
\hline Estado de São Paulo & 2,5 & 3,4 & 2,7 & 1,9 & 2,1 & 3,1 & 2,6 & 1,6 \\
\hline Grande São Paulo & 2,4 & 3,2 & 2,8 & 1,8 & 2,1 & 3,1 & 2,7 & 1,7 \\
\hline Registro & 3,8 & 5,1 & 3,7 & 2,5 & 3,2 & 4,9 & 3,6 & 2,0 \\
\hline Santos & 2,4 & 3,5 & 2,9 & 1,9 & 2,1 & 3,1 & 2,8 & 1,7 \\
\hline São José dos Campos & 2,7 & 3,7 & 2,9 & 2,1 & 2,2 & 3,4 & 2,7 & 1,8 \\
\hline Sorocaba & 2,9 & 3,8 & 3,0 & 2,1 & 2,4 & 3,3 & 2,9 & 1,8 \\
\hline Campinas & 2,5 & 3,3 & 2,7 & 1,9 & 2,1 & 3,0 & 2,6 & 1,6 \\
\hline Ribeirão Preto & 2,5 & 3,4 & 2,8 & 1,9 & 2,1 & 3,3 & 2,6 & 1,7 \\
\hline Bauru & 2,7 & 3,6 & 2,7 & 2,0 & 2,2 & 3,4 & 2,6 & 1,7 \\
\hline São José do Rio Preto & 2,2 & 2,8 & 2,4 & 1,8 & 1,9 & 2,7 & 2,2 & 1,6 \\
\hline Araçatuba & 2,4 & 3,2 & 2,6 & 1,9 & 2,0 & 2,7 & 2,4 & 1,6 \\
\hline Presidente Prudente & 2,5 & 3,2 & 2,7 & 2,0 & 2,1 & 3,0 & 2,5 & 1,8 \\
\hline Marília & 2,6 & 3,3 & 2,7 & 2,1 & 2,1 & 2,8 & 2,6 & 1,8 \\
\hline Central & 2,4 & 3,1 & 2,7 & 1,9 & 2,1 & 3,1 & 2,7 & 1,5 \\
\hline Barretos & 2,6 & 3,2 & 2,7 & 1,9 & 2,1 & 2,7 & 2,6 & 1,7 \\
\hline Franca & 2,6 & 3,5 & 2,7 & 2,2 & 2,4 & 3,1 & 2,7 & 1,9 \\
\hline
\end{tabular}

Fonte: Fundação IBGE. Censos D emográficos de 1991 e 2000, Fundação Seade.

O s dados do censo de 2000 revelam que a fecundidade diminuiu em todas as categorias e em todas as regiões, embora não se observe maior variação em um grupo ou outro (em geral, a menor diminuição ocorreu no grupo intermediário de nível de instrução). Em todas as regiões, as mulheres com mais de oito anos de instrução tiveram no máximo dois filhos, enquanto a fecundidade do grupo 
menos instruído variava entre 2,7 e 3,4 filhos. Como já mencionado, o aumento do nível de instrução das mulheres foi importante, de forma que, em 2000, as mulheres com até três anos de instrução correspondiam a $20 \%$ da população total feminina, as que tinham completado entre quatro e sete anos somavam $33 \%$ e um pouco menos da metade da população possuía mais de oito anos de instrução. D esta forma, não é de se estranhar que a fecundidade média já não seja tão elevada, devendo-se afastar a idéia de que as menos instruídas, ou extrapolando, que as "mais pobres" tenham muitos filhos, pois as mulheres com menor nível de instrução têm, em média, uma fecundidade de aproximadamente três filhos e correspondem à quinta parte da população; assim, mesmo existindo grupos de mulheres com elevado número de filhos, o seu peso na população é pequeno e elimina a possibilidade de influenciar o nível de fecundidade geral.

Assim, a diferença no número de filhos entre as mulheres com maior e menor nível de instrução é de aproximadamente 1,5 filho em 1991 e em 2000, o que é pouco, comparando-se às diferenças que existiam na década de 1980: 2,7 em 1980 e 2,3 em 1986 (Godinho e M orell, 1994). Essas diferenças, embora variadas, são também pequenas nas regiões, ou seja, o número de filhos entre os grupos extremos varia de um a dois filhos, conforme a região, com exceção de Registro, onde a diferença varia de 2,5 a três filhos.

As estruturas de fecundidade por idade das mulheres dos diferentes níveis de instrução possuem características específicas ( $G$ ráfico 3 ). As curvas das menos instruídas e do grupo intermediário caracterizam-se pela fecundidade das jovens de quinze a dezenove anos bastante elevada (entre cem e 150 nascimentos por mil), com a cúspide situando-se entre vinte e 25 anos, ou seja, uma estrutura de fecundidade mais jovem.

\section{Gráfico 3}

Taxas de Fecundidade por I dade, segundo o nível de instrução da mulher,

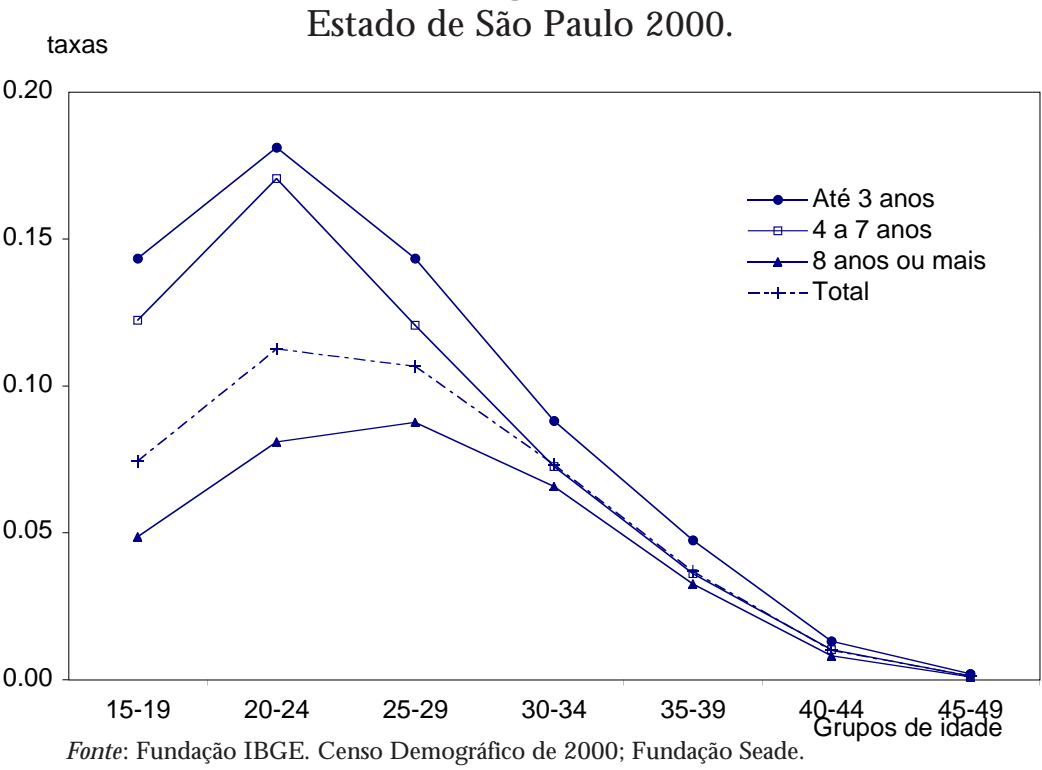


O grupo das mais instruídas caracteriza-se pelas taxas bastante inferiores aos dos grupos anteriores e a cúspide se situa entre 25 e trinta anos, portanto, com um padrão de fecundidade mais envelhecido. É interessante notar que a fecundidade das mulheres com mais de trinta anos aproxima-se nos três grupos de instrução, indicando forte controle da fecundidade, seguramente por meio da esterilização.

Esta análise da fecundidade por instrução da mulher permite, portanto, uma melhor compreensão do comportamento reprodutivo das mulheres dos diferentes grupos sociais de uma po pulação. R efinamentos podem ser realizados para definição de grupos para melhor caracterizar a população, entretanto, a principal tarefa consiste na busca dos fatores associados a essa contínua queda da fecundidade, inclusive abaixo do nível de reposição, nos diferentes setores populacionais.

\section{Conseqüências da queda da fecundidade}

A diminuição no ritmo de crescimento populacional e a mudança na estrutura da população em direção ao envelhecimento populacional são aspectos bastante conhecidos e discutidos como conseqüências da queda da fecundidade ocorrida no Estado de São Paulo, assim como em todo o país. Os dados demográficos mais recentes revelam as transformações ocorridas na dinâmica e nas características da população, isto é, confirmam a desaceleração no ritmo de crescimento populacional e mostram uma nova estrutura etária da população. No caso de São Paulo, outras variáveis demográficas também intervêm nessas mudanças, ou seja, a interação da fecundidade, da migração e da mortalidade determinará a taxa de crescimento paulista no futuro, bem como o padrão etário da população.

D iferentes níveis de fecundidade determinam estruturas etárias mais jovens ou mais envelhecidas da população e éa queda verificada nos níveis que determina o envelhecimento dessa estrutura. A velocidade dessa diminuição também é importante, pois uma queda rápida, lenta ou variável da fecundidade pode reduzir bruscamente o número de nascimentos e oscilar, de forma que a estrutura populacional pode adquirir saliências e reentrâncias acentuadas em diferentes grupos etários (C ampanário e Yazaki, 1994).

A redução da fecundidade do início dos anos de 1980 provocou diminuição da base da pirâmide etária da população, assim como sinalizou para o processo de envelhecimento da população. As projeções populacionais elaboradas pela Fundação Seade para os próximos vinte anos, com base nas tendências das variáveis demográficas no período 1980-2000, sinalizam para uma mudança total no perfil populacional paulista, que passaria de uma estrutura relativamente jovem - ainda com característica piramidal - para uma mais adulta, onde em cada faixa qüinqüenal de idade até os cinqüenta anos seria constituída por contingentes numericamente parecidos e a população com mais de sessenta anos seria mais numerosa. Em 
termos de grandes grupos etários, a população, em 2020, seria composta por $20,6 \%$ de pesso as com menos de quinze anos, $14,7 \%$ com mais de sessenta, sendo esta mais numerosa no sexo feminino, enquanto atualmente a população compreende $26,3 \%$ de menores de quinze anos e $9 \%$ com mais de sessenta anos (Fundação Seade, 1998, atualizada com os resultados das projeções).

O rápido aumento da população idosa, como conseqüência da diminuição da fecundidade e 0 aumento da sobrevida em idades adultas tem, por sua vez, inúmeros rebatimentos em termos de saúde pública, previdência, encargos para as famílias, entre outros. N a primeira área, as conseqüências são relativas à mudança do perfil de morbidade, pois com o aumento da população idosa, haverá o aumento do peso das doenças crônicas e degenerativas. No que diz respeito à previdência, a discussão é complexa, já que se somará ao problema atual de aposentadoria um crescente número de aposentados, os quais, por sua vez, permanecerão mais tempo usufruindo o benefício. A família passará a ter um papel importante de apoio no cuidado do idoso, já que nem o Estado, nem a sociedade estão preparados suficientemente para essa nova situação.

Enquanto nos países desenvolvidos o processo de envelhecimento foi acompanhado da elevação do nível de vida da população, o que se observa na nossa realidade e em outros países em desenvolvimento é que a melhoria das condições de vida de grande parcela da po pulação não está ocorrendo ou é ainda incipiente. D esta forma, há uma grande urgência para que o Estado e a sociedade se preparem para acompanhar esse rápido processo de envelhecimento populacional.

A mudança na estrutura etária da população também traz benefícios relacionados à redução da população infantil como, por exemplo, o atendimento da população em idade escolar ou a melhoria da co bertura vacinal. É o momento não somente de rever o número de vagas nas escolas, mas sobretudo de corrigir a distorção série/ idade existente na rede de ensino, assim como de beneficiar as famílias que necessitam de creches para as crianças em idade pré-escolar.

Frente a esses desafios, é necessária a elaboração de políticas e programas públicos e privados que atendam os diversos setores da sociedade; por outro lado, os estudos científicos são imprescindíveis, pois possibilitam maior conhecimento e fornecem insumos para a elaboração desses programas e políticas.

\section{Considerações finais}

O objetivo deste trabalho foi o de apresentar algumas características associadas à evolução da fecundidade no Estado de São Paulo, que registrou no início do ano 2000 uma taxa inferior a 2,1 filhos por mulher. A diminuição da fecundidade em São Paulo, assim como no Brasil, foi intensa, pois embora o processo tenha se iniciado nos grupos mais favorecidos da população, alcançou, em um menor espaço de tempo, todas as demais camadas da população. A evolução do padrão da fecundidade por idade é um importante aspecto na de sua transição, 
uma vez que sua redução aos baixos níveis foi obtida mesmo com a diminuição de sua idade média ou o aumento das taxas das jovens de quinze a dezenove anos, tendências contrárias às observadas em países com baixos níveis de fecundidade. Além disso, vale notar que este perfil foi observado em praticamente todas as regiões do Estado, apesar de suas diferenças socioeconômicas.

E mbora a fecundidade abaixo do nível de reposição seja um fenômeno ainda recente em São Paulo, a análise mostrou algumas alterações nas tendências em curso nas últimas décadas, como, por exemplo, a redução da fecundidade das adolescentes, após um período em que se manteve elevada e em ascensão, tendência ao aumento da idade média, revertendo a diminuiç̧ão que ocorria como resultado da fecundidade precoce; entre outras. E mbora não se espere recuperação importante nos níveis de fecundidade, dadas as características da queda em São Paulo e no país, é com interesse que se acompanha a evolução do comportamento reprodutivo nos próximos anos. O s diversos estudiosos do tema no país, em face a esta nova situação, têm retomado as inúmeras análises dos fatores determinantes associados à transição da fecundidade, a fim de avaliarem os possíveis comportamentos futuros da fecundidade (Goldani, 2002; Perpétuo e Wong, 2003).

N otas

1 Essa taxa é uma medida-resumo do nível de fecundidade em determinado ano e define-se como o número médio de filhos que teriam as mulheres de uma coorte hipotética ao fim de seus períodos reprodutivos. Assume-se que as mulheres não morrem durante o período fértil (entre quinze e cinqüenta anos) e que têm seus filhos segundo as taxas por idade observadas na população em questão, no ano de referência.

2 A expressão "nível de reposição" é utilizada quando a taxa de fecundidade total atinge o valor de 2,1 filhos por mulher, ou seja, o número médio de filhos que cada mulher deveria ter durante sua vida fértil para reposição de sua geração. $N$ a realidade, esse valor é uma aproximação, na medida em que o nível de reposição corresponde a um nível de fecundidade em que a taxa líquida de reprodução é exatamente igual a um, que depende da razão de sexo ao nascimento e da proporção de mulheres sobreviventes na idade média da fecundidade. Em geral, a razão de sexo varia entre 1,05 e 1,07 e a sobrevivência das mulheres em regiões de baixa mortalidade varia entre 0,97 e 0,99, de forma que a TFT de 2,1 filhos por mulher é utilizada como proxy do "nível de reposição".

3 D iversos estudos analisaram o fenômeno da gravidez na adolescência, dos problemas associados a uma gravidez inesperada e indesejada, das causas e conseqüências da precocidade da gravidez, entre outros aspectos (Yazaki et al., 1998; M adeira, 1997; M adeira e Wong, 1988; M elo, 1996; estudos apresentados na sessão "Gravidez e contracepção na juventude" do XIII Encontro de Estudos Populacionais da Abep, 2002, assim como em encontros anteriores; entre outros); portanto, para melhor compreensão deste tema, remetemos o leitor a estes estudos. 
4 Vale ressaltar que a comparação é estritamente quantitativa, na medida em que as realidades culturais, sociais, políticas são diversas nesses países, fatores que certamente influenciam o comportamento reprodutivo e os níveis de fecundidade de suas populações, assim como a evolução dos mesmos.

5 Estudos indicam que a prática da esterilização iniciou-se primeiramente entre as mulheres pertencentes ao s grupos mais privilegiados da população, estando associada ao parto cesáreo. Essa prática, entretanto, estendeu-se a todos os grupos sociais, criando-se uma "cultura de esterilização" (Berquó, 1993; Serruya, 1992; Perpétuo e Wajnman 1993, entre outros).

6 D iscussões sobre as estatísticas alarmantes da realização de cesáreas no país são inúmeras. Elas assinalam que "o valor histórico da cesárea como procedimento para salvar vidas, assim como suas vantagens, consideradas as precisas indicações, é inquestionável; as dúvidas quanto a seus benefícios estão relacionadas às indicações ampliadas de cesáreas e aos casos em que não existem razões médicas, sendo realizadas exclusivamente por conveniência da gestante ou do médico. Sakala (1993) adverte que muitas das cesáreas são praticadas sem indicação clínica, estimando-se que, caso estas fossem evitadas, dificilmente os percentuais seriam superiores a 25\%" (Yazaki et al., 1998; entre outros).

7 C itam-se, por exemplo, Carvalho e Wong (1996), Faria (1989) que discute as políticas de governo na regulação da fecundidade, M artine (1996), entre vários autores.

$8 \mathrm{D}$ ado que estas estimativas foram obtidas por meio de um méto do indireto, utilizando dados de amostra, os valores das TFTs estão sujeitos a variabilidades e, portanto, devem ser considerados como uma referência.

\section{Referências bibliográficas}

ABEP. A naisdoX III EncontroN acional deEstudosPopulacionais O uro Preto. D isponível em‘http:/ / www.abep.org.br, 2002.

BERQ U Ó , E. "Brasil. U m caso exemplar, anticoncepção e parto cirúrgico. A espera de uma ação exemplar". Apresentado no seminário A situação da mulher e o desenvolvi mento, organizado pelo M inistério das R elações Exteriores. Campinas, N epo/ U nicamp, 1993.

CAM ARGO , A. B. M . e YAZAKI, L. M . "A fecundidade recente em São Paulo: abaixo do nível de reposição?" Trabalho apresentado no XIII Encontro de Estudos Populacionais. O uro Preto, Abep, 2002.

CAM PANÁRIO, P. e YAZAKI, L. M. "A fecundidade em São Paulo e suas Regiões de Governo: níveis e tendências". I nforme Demográfico no 25. São Paulo, Fundação Seade, 1994.

CARVALHO, J. A. M. e WONG, L.R. "The fertility transition in Brazil: causes and consequences". Em GU ZM ÁN et al. (org.). TheFertilityTransition in Latin A merica. Oxford, Claredon Press, 1997.

FARIA, V. E. "Políticas de governo e regulação da fecundidade: conseqüências não antecipadas e efeitos perversos". Em Ciências sociais hoje: anuário de antropologia, política e sociologia. São Paulo, Anpocs, 1989. 
FERRANDO, D. "La fecundidad por edades en América Latina y sus perspectivas futuras". Seminario La fecundidad en A mérica Latina: transición orevolución? Santiago de Chile, Cepal, 2003.

FU NDAÇÃO SEADE. Cidadão do século XXI. São Paulo, 1998.

GODINHO, R. E. e MORELL, M. G. G. “U ma análise diferencial da fecundidade segundo variáveis sócio-econômicas (1980-1986)" . I nformeD emográfico, no 25. São Paulo, Fundação Seade, 1994.

GOLDANI, A. M. "What will happen to brazilian fertility?" Trabalho apresentado na U N C onferenceon TheExpert Group M eeting on "Completing theF er tilityTransition", N ew York, 2002.

H EN N IN G, S." La transición dela fecundidad en el M undo". Seminario La Fecundidad en A mérica Latina: Transición o R evolución? Santiago de Chile, CEPAL, 2003.

LAM , D., SED LACEK, G., eDU RYEA, S. “I ncreases in Women's Education and Fertility D ecline in Brazil". R esearch R eports, n 92-255, Population Studies Center, U niversity of M ichigan, 1992.

M ADEIRA, F. R. (org.).Quem mandou nascer mulher? Rio de J aneiro, R osa dosTempos, 1997.

M ADEIRA, F. R. e WO N G, L. R. "A ruptura precoce da vivência juvenil". E m 0 jovem na GrandeSão Paulo. São Paulo, Fundação Seade, 1988 (C oleção R ealidade Paulista).

M ARTINE, G. “Brazil'sFertility D ecline, 1965-95". Population and D evelopment R eview, vol. 22, no 1, 1996.

M ELO , A .V. “G ravidez na adolescência: uma nova ten dência na transição da fecundidade no Brasil". A nais do X Encontro N acional deEstudos Populacionais. Belo H orizonte, Abep, 1996.

PERPÉTU O , I. H . O . eWAJN M AN , S. “A esterilização feminina no Brasil: diferenciais por escolaridade e renda”. R evista Brasileira deEstudos dePopulação, vol. 10, n 1-2, Abep, 1993.

PERPÉTUO, I. H . O . eWONG, L. R. "Programas y políticas nacionales que afectaron el curso de la fecundidade en el Brasil". Seminario La fecundidad en A mérica Latina: transición o revolución? Santiago de Chile, Cepal, 2003.

ROSERO-BIXBY, L. "La fecundidad en Áreas M etropolitanas de América Latina: la fecundidad de reemplazo y más allá". Seminario La fecundidad en A mérica Latina: transición o revolución? Santiago de Chile, Cepal, 2003.

SERRU YA, S. “Ligação detrompaseimaginário feminino”. A naisdoVIII EncontroN acional deEstudosPopulacionais, vol. 2. Brasília, Abep, 1992.

U N ITED N ATI O N S. "Below Replacement Fertility". Population Bulletin of theU nited $\mathrm{N}$ ations. Special I ssue no 40-41. N ew York, 2000.

WONG, L. R." Tendência e perspectiva da fecundidade no Estado de São Paulo". I nforme Demográfico, no 19. São Paulo, Fundação Seade, 1986.

YAZAKI, L. M . et al. "Sexualidade, casamento, reprodução". Em M ADEIRA, F. R. e MAM ERI, C. P. (coords.). 20 anos no ano 2000. Estudos sociodemográficos sobre a juventude paulista. São Paulo, Fundação Seade, 1998.

YAZAKI, L. M. Féconditéet inégalitéssociales le cas del'Etat deSão Paulo desannées 80. 
L ouvain-la-N euve, I nstitut de D émographie. U niversité C atholique de L ouvain, tese de doutorado, 2002.

R ESU M o - este estudo apresenta um panorama da fecundidade no E stado de São Paulo e suas Regiões Administrativas que registra taxas de fecundidade abaixo do nível de reposição desde o início do ano 2000. Analisa-se a evolução dos níveis e das estruturas da fecundidade durante o perío do da queda da fecundidade, utilizando as estatísticas de nascimento do Registro Civil. A queda da fecundidade ocorreu por meio de seu rejuvenescimento, situação contrária à observada em países desenvolvidos, que registra taxas muito baixas.

A BSTRACT - this study provides an overview of fertility in the state of São Paulo and in the state's administrative zones with fertility rates below replacement level since 2000 . $U$ sing birth certificates statistics from the Civil Registry, the essay analyzes how fertility rates and structures evolved during this period of falling rates. The reduced fertility occurred because of the rejuvenation of fertility, the reverse situation found in developed countries where fertility rates are very low.

Lúcia Mayumi Yazaki é analista de projetos e demógrafa da Fundação Seade.

Texto recebido e aceito para publicação em 24 de setembro de 2003. 